\title{
BMJ Open Quality of essential newborn care and neonatal resuscitation at health facilities in Afghanistan: a cross-sectional assessment
}

\author{
Faridullah Atiqzai, ${ }^{1}$ Partamin Manalai, ${ }^{1}$ Sher Shah Amin, ${ }^{2}$ Karen M Edmond, ${ }^{3}$ \\ Malalai Naziri, ${ }^{3}$ Mohammad Samim Soroush, ${ }^{\oplus 4}$ Sharmina Sultana, ${ }^{3}$ \\ Khaksar Yousufi, ${ }^{3}$ Thomas van den Akker, ${ }^{5}$ Jelle Stekelenburg, ${ }^{6,7}$ Hannah Tappis ${ }^{\circledR, 9}$
}

To cite: Atiqzai F, Manalai P, Amin SS, et al. Quality of essential newborn care and neonatal resuscitation at health facilities in Afghanistan: a crosssectional

assessment. BMJ Open 2019;9:e030496. doi:10.1136/ bmjopen-2019-030496

- Prepublication history and additional material for this paper are available online. To view these files, please visit the journal online (http://dx.doi. org/10.1136/bmjopen-2019030496).

Received 25 March 2019 Revised 01 August 2019 Accepted 07 August 2019
Check for updates

(C) Author(s) (or their employer(s)) 2019. Re-use permitted under CC BY-NC. No commercial re-use. See rights and permissions. Published by BMJ.

For numbered affiliations see end of article.

Correspondence to Dr Hannah Tappis;

hannah.tappis@jhpiego.org

\section{ABSTRACT}

Objective To assess readiness and quality of essential newborn care and neonatal resuscitation practices in public health facilities in Afghanistan.

Design Cross-sectional assessment.

Setting 226 public health facilities in Afghanistan, including 77 public health facilities with at least five births per day (high-volume facilities) and 149 of 1736 public health facilities with fewer than five births per day (lowvolume facilities).

Participants Managers of 226 public health facilities, 734 skilled birth attendants (SBAs) working at these facilities, and 643 women and their newborns observed during childbirth at 77 high-volume health facilities.

Outcome measures Availability of knowledgeable SBAs, availability of supplies and compliance with global guidelines for essential newborn care and neonatal resuscitation practices.

Results At high-volume facilities, 569/636 (87.9\%) of babies were dried immediately after birth, 313/636 $(49.2 \%)$ were placed in skin-to-skin contact with their mother and 581/636 (89.7\%) had their umbilical cord cut with a sterile blade or scissors. A total of 87 newborn resuscitation attempts were observed. Twenty-four of the $87(27.5 \%)$ began to breath or cry after simply clearing the airway or on stimulation. In the remaining $63(72.5 \%)$ cases, a healthcare worker began resuscitation with a bag and mask; however, only $54(62 \%)$ used a correct size of mask and three babies died as their resuscitation with bag and mask was unsuccessful.

Conclusions The study indicates room for improvement of the quality of neonatal resuscitation practices at public health facilities in Afghanistan, requiring only strengthening of the current best practices in newborn care. Certain basic and effective aspects of essential newborn care that can be improved on with little additional resources were also missing, such as skin-to-skin contact of the babies with their mother. Improvement of compliance with the standard newborn care practices must be ensured to reduce preventable newborn mortality and morbidity in Afghanistan.
Strengths and limitations of this study

- This study addresses a gap in evidence on quality of newborn care in Afghanistan, and globally.

- Quality of care was only observed at facilities with an average of at least five births per day, and cannot be generalised to facilities with smaller caseloads.

- No data on client experiences of care were collected. Although this is an essential component of healthcare quality, it was outside the scope of this assessment.

\section{INTRODUCTION}

Despite substantial improvements, the Islamic Republic of Afghanistan still has unacceptably high newborn mortality, estimated at 40 per 1000 live births. ${ }^{12}$ Addressing maternal and newborn mortality is among the highest priorities of the Government of Afghanistan. ${ }^{34}$ The leadership of the Ministry of Public Health (MoPH) has emphasised the need to improve quality, access and ensure equitable delivery of life-saving maternal and child health interventions in the community and health facilities. ${ }^{4}$

Most cases of birth asphyxia, which causes approximately one-fourth of all neonatal deaths globally, are preventable and treatable, and there is clear evidence that low-cost, low-technology interventions can substantially reduce maternal and newborn mortality risk, especially for very small newborns. ${ }^{5-7}$ While the term 'essential newborn care' can be used in a variety of ways, the $\mathrm{WHO}$ and the Healthy Newborn Network use the term to refer to key routine practices in the care of the newborn at the time of birth and over the first hours of life, including early initiation and exclusive breast feeding; thermal care (including prompt drying and covering at birth, maximising skin-to-skin contact, delayed bathing, 
maintaining 'warm chain'); hygiene practices (including cord-care and caregiver handwashing); umbilical cord care, eye care, vitamin $\mathrm{K}$ administration and immunisation. ${ }^{89}$

Improving quality of healthcare requires attention to systems and organisation of care as well as a focus on individual providers and supplies. ${ }^{10}{ }^{11}$ Services at all public facilities in Afghanistan are standardised, including a basic package of health services (BPHS) for primary healthcare facilities and essential package of hospital services (EPHS).$^{12}$ All public health facilities, from basic health centres to specialty hospitals, are expected to provide essential newborn care and newborn resuscitation among many other curative interventions. ${ }^{4}$

Assessing quality of care requires an understanding of the national programme and policies, facility readiness, health worker competencies, health worker-patient interactions, user experiences and the environment in which services are provided. ${ }^{13-15}$ Although there have been many assessments of facility readiness and health service capacity in Afghanistan, including a 2010 National Emergency Obstetric and Newborn Care needs assessment at first-line referral facilities and annual assessments of BPHS and EPHS facilities, there have been no largescale facility assessments in documenting the quality of essential newborn care and compliance with global clinical practice standards. ${ }^{3} 1617$

The objectives of this assessment were to examine readiness for essential newborn care and neonatal resuscitation at all levels of the public health system, and to document actual care practices at public health facilities with five or more births per day.

\section{METHODS}

The National Maternal and Newborn Health Quality of Care Assessment, a cross-sectional health facility assessment covering 266 health facilities across all 34 provinces of Afghanistan, was conducted in 2016. This study is a subset of the assessment focused on quality of newborn care practices; quality of maternal care practices is reported elsewhere. ${ }^{18}$

\section{Study sites}

The study assessed facility readiness and observed quality of care at all accessible public facilities with an average of five or more births per day as per national health management information system data from the year 1394 of the Solar calendar (March 2015-March 2016 Gregorian). Two of the 79 public facilities with an average of five or more births per day were inaccessible due to insecurity during the assessment period. Readiness to provide maternal and newborn health services was also assessed at a representative sample of public facilities providing less than five births per day that were accessible at the time of the survey. The sample size was calculated for a finite population of 1736 facilities with less than five births per day, a $10 \%$ margin of error, $5 \%$ alpha error, a design effect of 1.5 due to stratification of facility types; and a $5 \%$ oversampling for possible loss due to inaccessibility. A total of 266 health facilities, including 77 of 79 public facilities with at least five births per day and 149 randomly selected from among 1736 public facilities with less than five births per day were visited between May and December 2016.

\section{Data collection}

Facility readiness for newborn health service provision was defined as availability of human resources, equipment and supplies at the point of care. Readiness assessment activities conducted at all facilities through included documentation of the availability of human resources, equipment, medicines and supplies, as well as interviews with skilled birth attendants (SBAs) serving at the time of the study. A maximum of five SBAs were invited to participate in the study at each facility, except for specialty hospitals where five SBAs on the day shift and five SBAs on the night shift were invited to participate. Structured clinical observation checklists (see online supplementary material), adopted from similar studies conducted by the United States Agency for International Development (USAID)-funded Maternal and Child Health Integrated Program ${ }^{19}$ that were based on WHO guidelines, ${ }^{8}$ as well as the Demographic and Health Survey, Service Provision Assessment, ${ }^{20}$ and Emergency Obstetric and Newborn Care Assessments supported by the Averting Maternal Death and Disability Program, ${ }^{21}$ were used to assess the quality of services provided by the SBAs at the 77 high-volume public health facilities with an average of at least five births per day. Observers were instructed to wait for cases of delivery in the delivery room, and aimed to observe five births. Moreover, five cases, not necessarily the same as those observed during their delivery, were visited at the postpartum wards. In the specialty hospitals both day shifts and night shifts were observed. All instances of newborn resuscitation occurring during visits to health facilities were observed.

Data collectors were midwives and doctors who received clinical updates and theoretical and practical training in data collection methodologies, including observation practice to ensure inter-rater reliability. All data collectors were unemployed or took a leave of absence from clinical work to serve as data collectors, and did not assess quality of care at health facilities in their home province. Data collection was carried out in the second half of 2016 using CommCare software installed on Android tablets, allowing for logic and consistency checks and quality control, and online submission of the data to a central database.

\section{Analysis}

First, descriptive statistics for newborn care service readiness, provider knowledge of newborn care, observation of newborn care during normal labour and observation of newborn resuscitation services were used for analysis. Numbers and percentages of facilities meeting the 
requirements for provision of quality newborn care were calculated and presented by type of input and type of facility. Numbers and percentages of healthcare providers responding correctly to the knowledge assessment questions were presented similarly. Then, frequencies and proportions of observed cases in which the clients received the services according to the standards were calculated. Simple logistic regression was used to assess and compare odds of adhering to global guidelines for routine care practices by public facility type. Finally, observations of newborn resuscitation were analysed as a series of case studies; no statistical analysis was conducted. Qualitative field notes were used for cleaning and cross-validation of findings documented in observation checklists. All analyses were conducted using Stata version 15 .

\section{Patient and public involvement}

Neither patients nor the public were involved in the development of research questions or outcome measures. Results were disseminated to staff of facilities participating in this study through MoPH officials, non-governmental organisation and health professional association members participating in national and provincial level dissemination workshops.

\section{RESULTS}

A total of 226 health facilities were included in the assessment, 734 SBAs working at these facilities participated in interviews, and 643 clients at 77 of the 226 health facilities with an average of at least five births per day were observed. Birth caseloads varied dramatically by facility type, as expected. Facility logbooks recorded an average of 729 births per month at high-volume specialty, regional and provincial hospitals, 300 births per month at high-volume district hospitals and comprehensive health centres, and 15 or fewer births per month at other primary healthcare facilities (including comprehensive health centres, basic health centres, sub-health centres and family health houses) (table 1).

\section{Facility readiness for essential newborn care provision \\ Availability of competent health workers}

All specialty, regional and provincial hospitals $(n=37)$ reported having SBAs on duty or on call 24 hours per day, 7 days per week. District hospitals and comprehensive health centres are also expected to have SBAs on duty or on call 24 hours per day, 7 days per week; however, only 61 of 77 district hospitals and comprehensive health centres assessed reported having staff on duty round-the-clock. Of the 734 SBAs interviewed across all levels of facilities, only 218/734 (29.7\%) reported having received training on essential newborn care in the last 3 years, and 238/734 $(32.4 \%)$ reported having received training on resuscitating newborns not breathing at birth. Fewer reported having received training on basic or comprehensive emergency obstetric and newborn care (table 1).
Interviews revealed notable gaps in knowledge of essential newborn care among SBAs. Across all levels of facilities, knowledge of basic equipment and supplies that must be available to ensure every baby receives appropriate immediate care after birth was lacking; 105/734 (14.3\%) of SBAs could name all eight essential items listed in table 1. A total of 131/734 (17.9\%) SBAs could list all key aspects of essential newborn care including thermal protection, cutting the cord, breast feeding within 1 hour, assessing the newborn within 1 hour and newborn eye care. Across all levels of facilities 260/734 (35.4\%) of SBAs could name steps to perform neonatal resuscitation on a baby who is not breathing and for whom back rubbing does not help (table 1). Knowledge of newborn danger signs to check for during postnatal examinations was also limited; $<70 \%$ of SBAs named any of the danger signs listed in table 1. Overall, the knowledge scores of SBAs about essential newborn care were higher for providers at District Hospitals (DHs), Comprehensive Health Centres (CHCs) and Basic Health Centres (BHCs) as compared with those at $\mathrm{SH} / \mathrm{RHs}$ and PHs (table 1).

\section{Availability of essential supplies}

Less than $50 \%$ of the 226 public health facilities assessed had clinical guidelines for essential newborn care, emergency obstetric and newborn care, and prereferral management of obstetric and newborn complications available in the delivery room. Assessment visits also revealed gaps in availability of essential supplies at the point of care. While the majority of facilities $(92.5 \%, \mathrm{n}=209)$ had sterile blades and $(82.3 \%, \mathrm{n}=186)$ had sterile cord ties/clamps available in the delivery room, $53.8 \%(\mathrm{n}=60)$ had towels/blankets available to ensure newborns are warm and dry. One or more item of the essential supplies needed for resuscitation of babies not breathing at birth were also lacking at all levels of facility. A total of $71.7 \% \quad(n=165)$ of facilities had a functional suction device for mucus extraction in the delivery room. Of facilities visited, $64.8 \%(\mathrm{n}=157)$ had a size 0 mask, $74.9 \%(\mathrm{n}=175)$ had a size 1 mask and $82.7 \%$ $(n=191)$ had a newborn sized ambu bag. Availability of supplies and equipment varied by item, with no clear patterns across facility types (table 2).

\section{Implementation of evidence-based essential newborn care practices}

A total of 643 clients were observed during labour, delivery and/or postpartum ward rounds before discharge. Not all clients were observed at all stages of care.

During observation of 636 births, $87.9 \%$ of babies $(\mathrm{n}=569)$ were dried immediately after birth, $49.2 \%$ $(n=313)$ were immediately placed in skin-to-skin contact with the mother, and an SBA cut the cord of $89.7 \%$ $(n=581)$ of the babies with a sterile blade or scissors. During the first hour after birth, an SBA checked the temperature of $22.1 \%$ of newborns ( $\mathrm{n}=143)$, a total of $32.1 \%$ of newborns $(\mathrm{n}=204)$ remained in skin-to-skin contact with their mother and $38.4 \%$ of women $(n=244)$ were assisted to start breast feeding within first hour after 


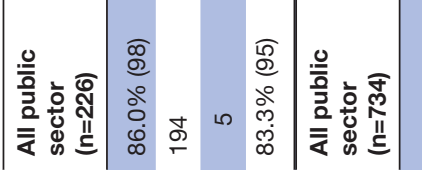

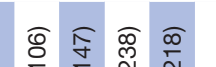

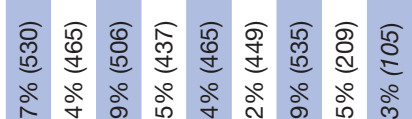

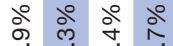

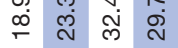

तิ

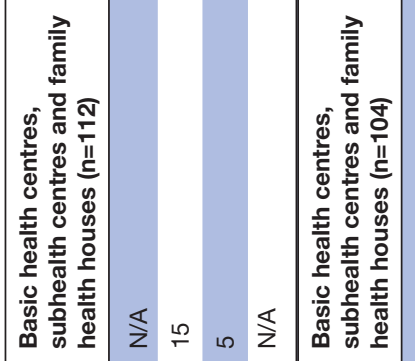

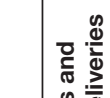

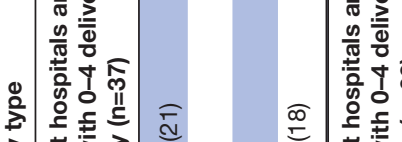

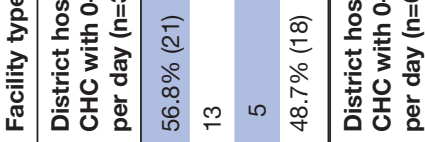

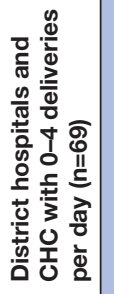

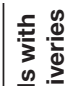

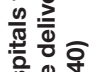

\section{急}

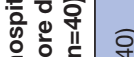

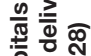

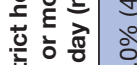

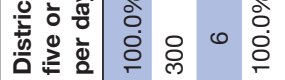

亭

하응

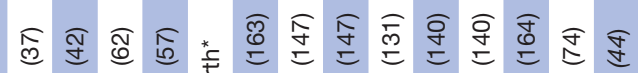

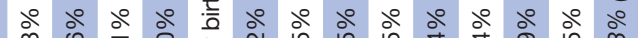

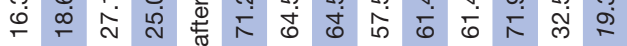

$\overline{\mathrm{\sigma}}$

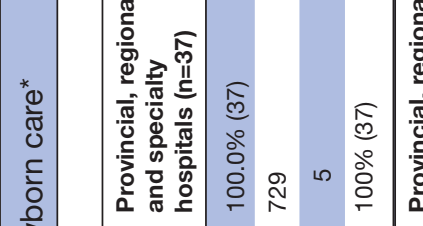

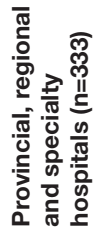

क्ल

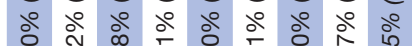

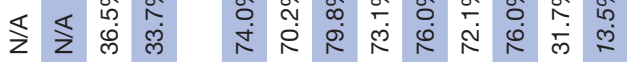

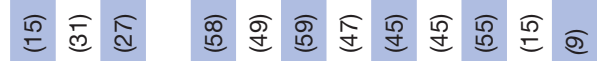

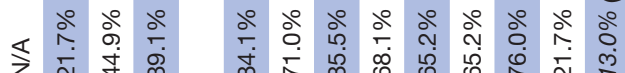

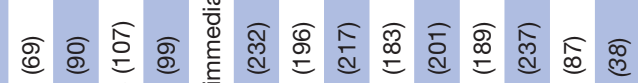

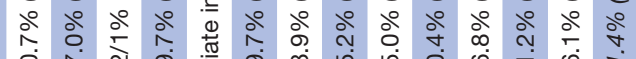
守

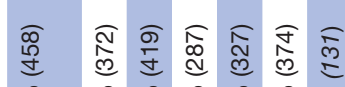

วั

ช

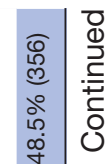

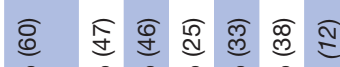

尔

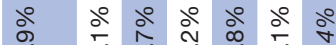

का

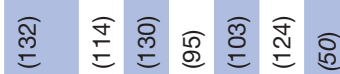

$\stackrel{0}{\varrho}$

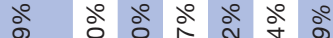

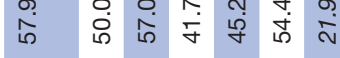

응

$\stackrel{0}{\circ}$

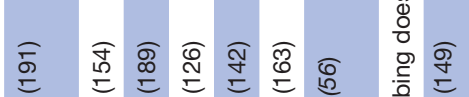

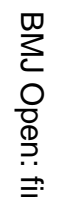

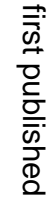

क

$\stackrel{\overrightarrow{0}}{\rightarrow}$

$\omega$

공.

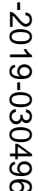

웅

$\omega$

突

$\stackrel{\text { क }}{\stackrel{4}{9}}$

옹

인

方

$\frac{0}{0}$

을

륨

혼

$\frac{0}{0}$

훙

ํํำ

웅

공.

N

ก

造

$\stackrel{0}{\stackrel{0}{\mathbb{D}}}$

꿍

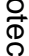

$\stackrel{\frac{1}{10}}{\stackrel{9}{10}}$

8

흘 


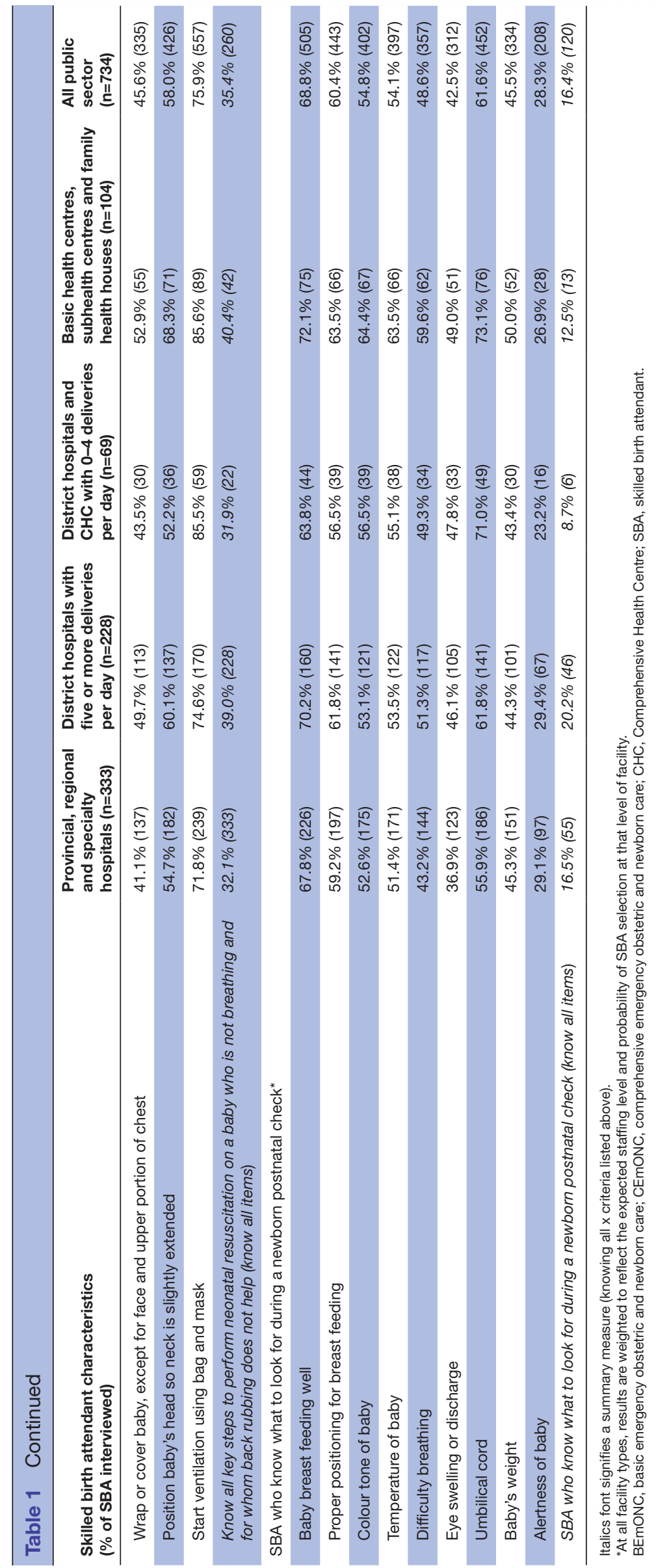




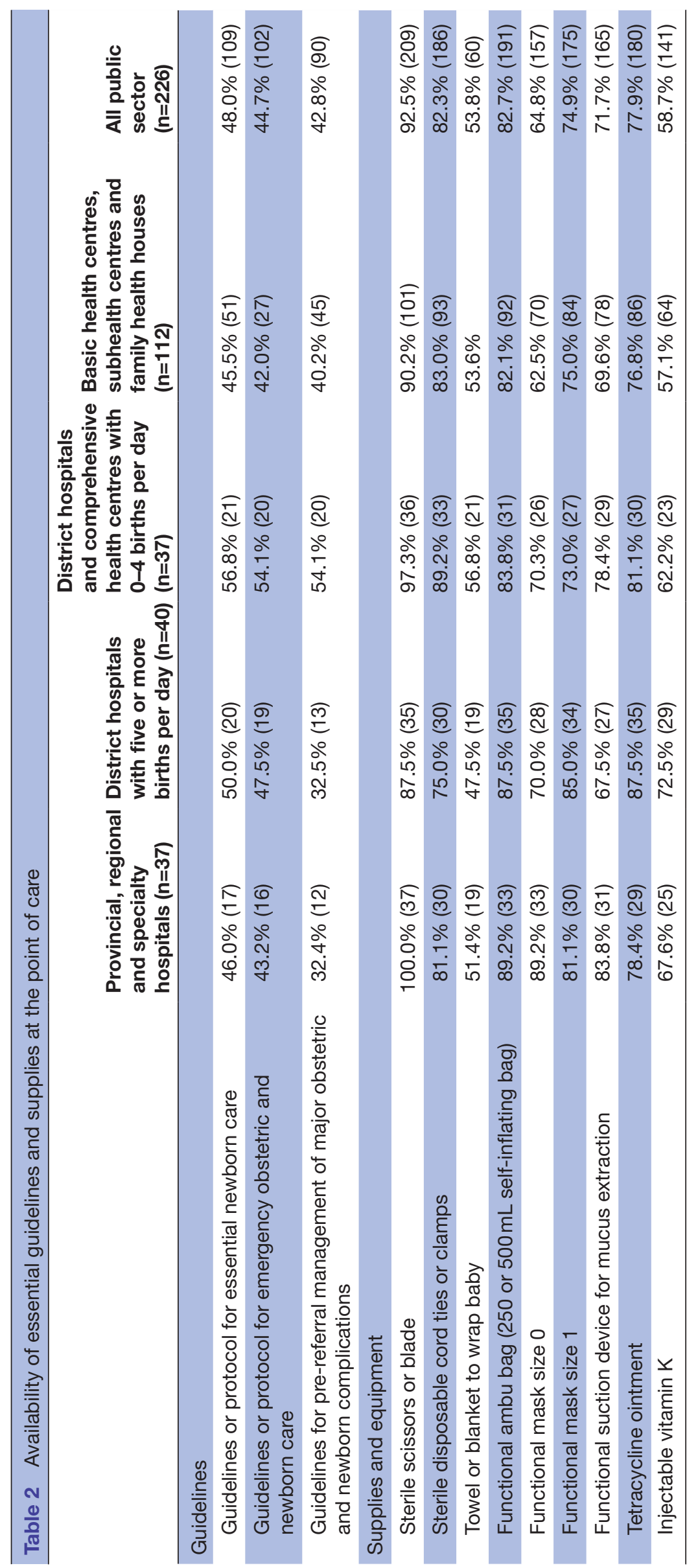


birth. The odds of initiating breast feeding within the first hour after birth was significantly lower at provincial, regional and specialty hospitals compared with district hospitals (unadjusted OR $0.44,95 \%$ CI 0.31 to 0.62 ). Eye care was provided to $42.3 \%$ of newborns $(\mathrm{n}=269)$ and vitamin $\mathrm{K}$ was administered to $33.7 \%(\mathrm{n}=214)$. There was no statically significant difference in the odds of immediate newborn practices at district hospitals compared to provincial, regional and specialty hospitals. During postpartum ward rounds, $11.5 \%(\mathrm{n}=73)$ of women received information from SBAs about danger signs that indicate a need for immediate care. The odds of explaining the danger signs were significantly lower at provincial, regional and specialty hospitals compared with district hospitals (unadjusted OR $0.49,95 \%$ CI 0.28 to 0.84 ) (table 3).

Other practices, which are no longer recommended, were documented in a small but notable proportion of births observed. One newborn $(0.2 \%)$ was bathed within the first hour after birth, and $90(14.2 \%)$ of newborns had their mouth and nose aspirated without any indication. In addition, $12(1.9 \%)$ newborns were slapped by health providers and $29(4.6 \%)$ were held upside down after birth, both of which are not recommended practices (table 4).

During assessment visits, a total of 87 newborn resuscitation attempts were observed at 39 of the 77 public hospitals with an average of at least five births per day. In $87.4 \%(n=76)$ of cases, a healthcare worker cleared the newborn's airway and rubbed its back to stimulate airflow. In $10.3 \%(\mathrm{n}=9)$ of cases, either the airway was cleared $(8.0 \%, \mathrm{n}=7)$ or stimulation given $(2.3 \% ; \mathrm{n}=2)$ but not both. Twenty-four of the 87 newborns not breathing at birth $(27.6 \%)$ began to breathe or cry after these simple actions. In the remaining 63 cases (72.4\%), a healthcare worker began resuscitation efforts with a bag and mask. Quality of resuscitation efforts varied. Of the 63 cases where health workers attempted bag and mask resuscitation, $84.1 \%(\mathrm{n}=53)$ had newborns correctly positioned with their heads properly extended; $85.7 \%(\mathrm{n}=54)$ used a correct size of mask, $87.3 \% \quad(\mathrm{n}=55)$ checked for secretions, $76.2 \% \quad(\mathrm{n}=48)$ had the mask correctly sealed and $74.6 \%(\mathrm{n}=47)$ checked if the newborn's chest was moving while ventilating. Health workers involved in resuscitation only called for additional help in $26.4 \%$ ( $n=23$ ) of 87 cases. Not all bag and mask resuscitation attempts were successful. Of the 63 cases observed, at least $79.4 \%(n=50)$ were successful and $4.8 \%(n=3)$ were not. Final outcomes of ten cases were not recorded by clinical observers; three newborns not crying after initial bag and mask resuscitation were transferred to special care and seven observations ended before an outcome was recorded (figure 1).

\section{DISCUSSION}

Service readiness for essential newborn care and some essential newborn care practices was limited in our large cross-sectional study conducted across all 34 provinces of Afghanistan. Quality of care appeared limited in both small and large facilities and system strengthening is needed at all levels of the health system.

Overall, SBA knowledge of essential newborn care was slightly higher at district hospitals and primary healthcare facilities compared with provincial, regional and specialty hospitals where the majority of facility births occur. This could be because the lower volume facilities managed by non-governmental organizations (NGOs) have greater autonomy in decision making over staff capacity building, and may suggest that facilities with fewer staff and lower caseloads provide a more flexible environment for on-the-job learning and knowledge retention. Readiness of facilities to address birth asphyxia was also concerning at all levels. Facilities lacking equipment such as proper size of facemask, lack of a resuscitation table in immediate proximity of the delivery table, and gaps in providers' knowledge of newborn resuscitation procedures were common challenges that have also been documented in neighbouring countries. ${ }^{22} 23$

Observations of clinical services revealed that too few babies born in facilities in Afghanistan receive evidencebased essential newborn care such as drying, skin-toskin contact, and temperature checks every $15 \mathrm{~min}$. In addition to inadequate knowledge of essential newborn care and resuscitation practices, these findings suggest a noteworthy 'know-do gap', particularly with regards to low-cost, high-impact practices that do not require specialised supplies or equipment, such as thermal care, delayed cord clamping and breast feeding support. A similar study conducted in six sub-Saharan African countries also found noteworthy gaps in essential newborn care practices; early initiation of breast feeding, immediate skin-toskin contact and delayed cord clamping were performed for less than three-quarters of the observed deliveries. ${ }^{19}$ A 12-country analysis of bottlenecks in implementation of the UN's Every Newborn Action Plan, which included Afghanistan, reinforced the importance of focusing investments on frontline care providers, and highlighted the need for more supportive supervision and programme monitoring to ensure capacity building and performance improvement efforts are effective. ${ }^{6}$

Predischarge examinations, postpartum counselling on newborn danger signs as well as counselling on postpartum care was lacking in most of the health facilities. Very few women were counselled on newborn danger signs immediately after delivery or during postnatal ward rounds. Given that average length of stay in facilities is $<6$ hours after delivery, this may result in missed opportunities for timely detection and management of complications in women and newborns. Studies assessing quality of other aspects of healthcare have also identified weaknesses in examinations and counselling practices. ${ }^{24} 25$ Greater emphasis on the importance of provider's counselling skills to teach women on the detection of danger signs at home is needed, as well as on the importance of examinations for reducing preventable newborn mortality. 


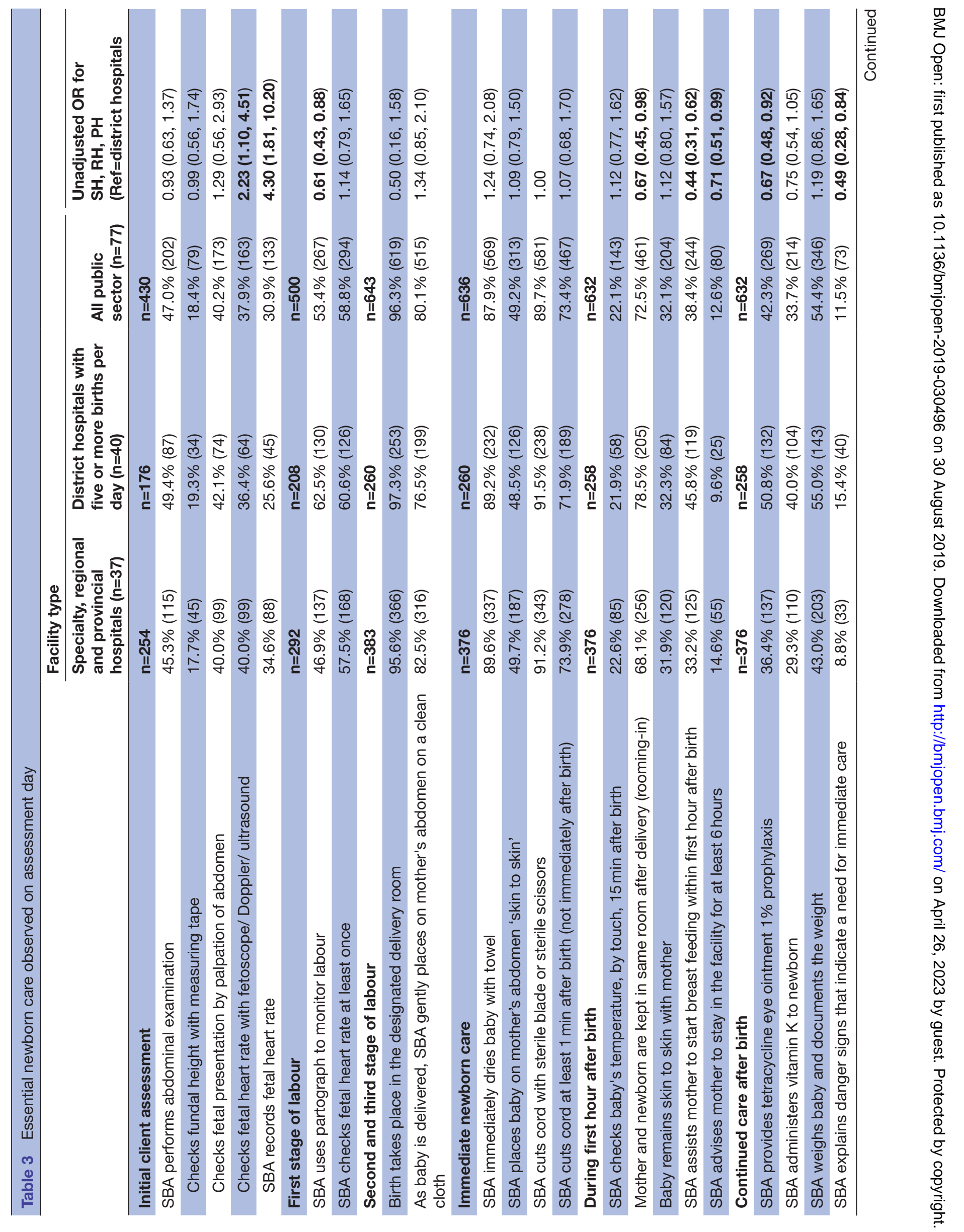




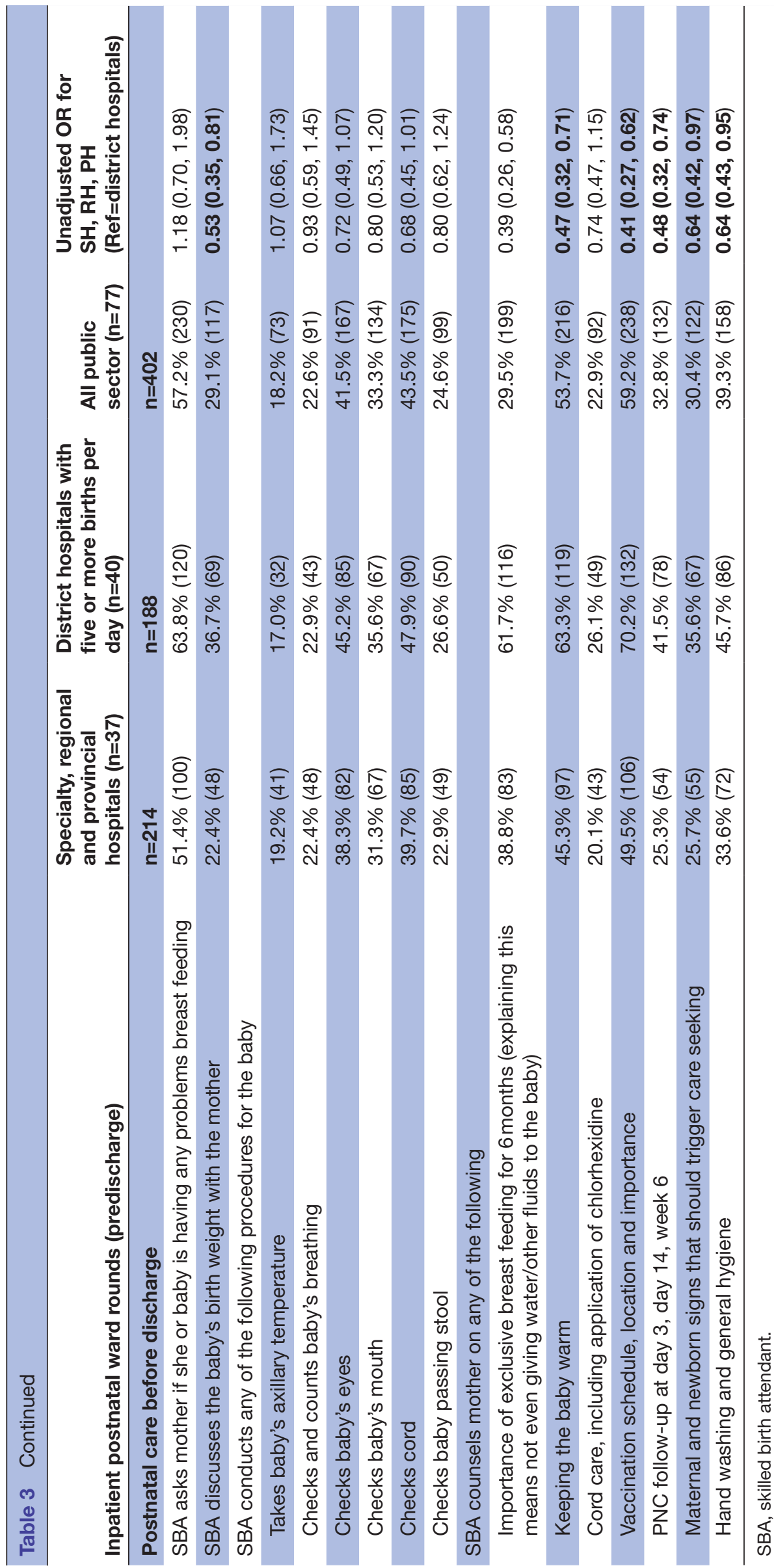


Table 4 Potentially harmful practices observed during assessment visit

\begin{tabular}{ll}
\hline \% of births observed & $\begin{array}{l}\text { All public } \\
\text { sector } \\
\text { (n=636) }\end{array}$ \\
\hline $\begin{array}{l}\text { Harmful or inappropriate practices that are never } \\
\text { indicated }\end{array}$ \\
$\begin{array}{l}\text { Bathing of newborn within first hour after birth } \\
\text { Practices done without an appropriate indication }\end{array}$ & $0.2 \%(1)$ \\
\hline $\begin{array}{l}\text { Routine aspiration of newborn mouth and nose } \\
\text { at birth }\end{array}$ & $14.2 \%(90)$ \\
\hline $\begin{array}{l}\text { Disrespectful or abusive practices } \\
\quad \text { Slapping newborn }\end{array}$ & $1.9 \%(12)$ \\
\hline Holding newborn upside down & $4.6 \%(29)$ \\
\hline
\end{tabular}

Evidence shows that up to $10 \%$ of babies require support to breathe during the first minutes of life, many of which can be saved with simple stimulation, and others with bag and mask ventilation. ${ }^{26}$ The observation of resuscitation documented instances of incorrect or omitted steps essential for successful resuscitation of the newborn that reveals skills gap among the providers. Maintenance of resuscitation skills requires ongoing practice and periodic refresher training through on-site and off-site courses and mentorship. ${ }^{27}$ Investment in capacity-building efforts focused on high-volume facilities where the majority of

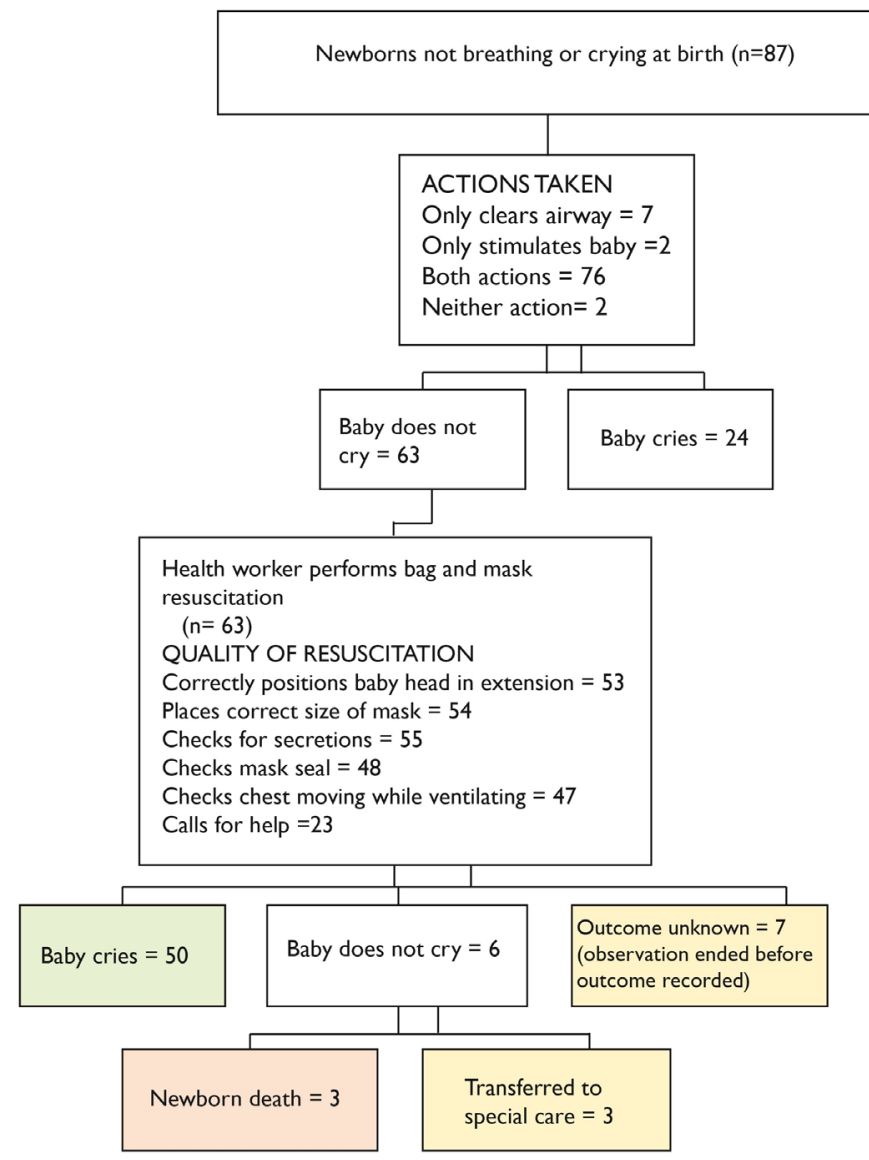

Figure 1 Care for newborns not breathing or crying at birth. births occur will yield greatest gains; however, because resuscitation must take place within the 'golden minute' after birth, any skills building initiatives to address the gaps in performance need to be considered for all facilities irrespective of their patient loads.

Although this study uses a robust methodology to assess quality of essential newborn care at health facilities in Afghanistan, it is not without limitations. First, quality of care was only directly observed at public facilities with an average of five or more deliveries per day. These 77 facilities account for approximately two-thirds (64\%) of the births reported at public facilities in 2015-2016, but we cannot generalise findings to the 1714 public health facilities with an average of $0-4$ births per day in the same year. Second, data were extracted from a larger study that was not designed specifically to explore quality of essential newborn care, so some aspects of care could not be explored in as much depth as other more focused studies. For example, we cannot assess the relationship between individual provider knowledge and performance; the units of analysis for this assessment were the health facility and case (client-provider interaction), and the same provider may have been observed providing care to multiple clients. Similarly, essential newborn care practices were only observed for babies born via normal vaginal delivery and immediately crying at birth; we did not document essential newborn care provided to babies born via caesarean surgery or following resuscitation of newborns not breathing or crying at birth. Finally, not recommended, potentially harmful and unindicated practices may be underreported due to the Hawthorne effect with the presence of clinical observers, indicating the real situation might be even worse. Nevertheless, this study provides new information on the current capacity of the Afghan health system and identifies areas for improvement to further reduce preventable newborn mortality and morbidity.

To address the challenges in routine newborn care as well as in resuscitation of babies suffering from birth asphyxia, the MoPH should invest in improving skills and knowledge of staff by providing in-service capacity building opportunities for staff at all levels of health facility. Approaches identified as solutions for intervention-specific bottlenecks, that is, mentorship, clinical peer practice, establishment of mini training centres equipped with anatomical models and regular staff capacity assessment may help providers to save more lives. ${ }^{6}$

In addition, stronger accountability mechanisms are needed to ensure access to quality services. Afghanistan's National Reproductive, Maternal, Newborn, Child and Adolescent Health Strategy 2017-2021 highlights the need to decongest overcrowded tertiary hospitals and improve access to essential newborn care practices and neonatal resuscitation at all levels of health facilities. ${ }^{4}$ Training and provision of essential supplies for newborn care are necessary, but not sufficient, to ensure all babies born at health facilities have access to quality care. Strong clinical leadership, institutionalising a culture 
of practical learning and quality improvement are also critical. $^{27}$

\section{CONCLUSIONS}

A number of essential newborn care and neonatal resuscitation practices at public health facilities in Afghanistan appear suboptimal. Healthcare provider knowledge of evidence-based practices is limited, and there are many missed opportunities for prevention and detection of newborn complications. Policymakers should focus on closing the gap between knowledge and practice of frontline SBAs. Identified gaps in quality of care must be addressed to reduce preventable newborn mortality and morbidity in Afghanistan.

\section{Author affiliations}

${ }^{1}$ HEMAYAT Project, Jhpiego Afghanistan, Kabul, Afghanistan

${ }^{2}$ Office of Health and Nutrition, USAID Afghanistan, Kabul, Afghanistan

${ }^{3}$ Health Section, UNICEF, Kabul, Afghanistan

${ }^{4}$ Reproductive, Maternal, Newborn and Child Health Department, Ministry of Public Health, Kabul, Afghanistan

${ }^{5}$ Department of Obstetrics, Leiden University Medical Center, Leiden, The Netherlands

${ }^{6}$ Department of Health Sciences, Global Health, University Medical Centre Groningen, Groningen, The Netherlands

${ }^{7}$ Obstetrics and Gynaecology, Leeuwarden Medical Centre, Leeuwarden, The Netherlands

${ }^{8}$ Technical Leadership Office, Jhpiego, Baltimore, Maryland, USA

${ }^{9}$ Department of International Health, Johns Hopkins University Bloomberg School of Public Health, Baltimore, Maryland, USA

Acknowledgements The authors would like to thank UNICEF and USAID for funding the study and technical collaboration, central and provincial MoPH offices for their guidance and support, the non-governmental organisations implementing Afghanistan's health care services, and those professionals who participated in the study. Special thanks to Sherin Varkey from UNICEF; Sayed Attaullah Saeedzai, MoPH General Director of Evaluation and Health Information System; Zelaikha Anwari, MoPH Director of Reproductive, Maternal, Newborn Child and Adolescent Health Department; Catherine Todd, Associate Director, Reproductive, Maternal, Newborn Child Health Division, FHI360; and Pasty Bailey, Senior Scientist Health Services Division, FHI360; Nasratullah Ansari, Zahra Sultani, Sayed Esmati, Ahmad Eklil Hussain, Mahmood Azimi, Enayatullah Mayar, Niaz Popal, Abdul Qader Rahimi, Raouf Saidzadah, Matiuallah Noorzad and Laila Natiq from Jhpiego Afghanistan; Barbara Rawlins, Sheena Currie, Elizabeth Sasser and Grace Jacoby from Jhpiego Baltimore; facility staff participating in the study; and women allowing observation of care. Thanks to all the midwives and doctors who served as data collectors in very difficult situations.

Contributors FA and PM served as coinvestigators for the 2016 Afghanistan National Maternal and Newborn Health Quality of Care Assessment, contributed to the analysis, led and contributed to the interpretation of study findings, and to writing and revision of the manuscript. SSA, KME, MN, MSS, SS and KY contributed to the interpretation of study findings, and to writing and revision of the manuscript. JS served as a study advisory board member and contributed to the review and revision of the manuscript. TvdA contributed to the review and revision of the manuscript. HT served as the principal investigator, led the data analysis, and contributed to the interpretation of study findings, and to writing and revision of the manuscript. All authors read and approved the final manuscript.

Funding This work was supported by the United States Agency for International Development (USAID) Afghanistan FP/MNCH Project (AID-306-A-15-00002) and UNICEF Afghanistan National Maternal and Newborn Health Quality of Care Assessment award (0060/A0/07/881). The contents of this manuscript are the responsibility of the authors and do not necessarily reflect the views of the funders.

Competing interests None declared.

Patient consent for publication Obtained.
Ethics approval The study was approved by the Institutional Review Boards of the Ministry of Public Health of Afghanistan (IRB\# 361533) and the Johns Hopkins Bloomberg School of Public Health in Baltimore, Maryland (IRB\# 6799).

Provenance and peer review Not commissioned; externally peer reviewed.

Data availability statement Data are available upon reasonable request. Data may be obtained from a third party and are not publicly available.

Open access This is an open access article distributed in accordance with the Creative Commons Attribution Non Commercial (CC BY-NC 4.0) license, which permits others to distribute, remix, adapt, build upon this work non-commercially, and license their derivative works on different terms, provided the original work is properly cited, appropriate credit is given, any changes made indicated, and the use is non-commercial. See: http://creativecommons.org/licenses/by-nc/4.0/.

\section{REFERENCES}

1. Boerma T, Requejo J, Victora CG, et al. Countdown to 2030: tracking progress towards universal coverage for reproductive, maternal, newborn, and child health. Lancet 2018;391:1538-48.

2. United Nations Inter-agency Group for Child Mortality Estimation (UN IGME). Levels \& Trends in Child Mortality: Report 2018, Estimates developed by the United Nations Inter-agency Group for Child Mortality Estimation. New York: United Nations Children's Fund, 2018.

3. Naziri M, Higgins-Steele A, Anwari Z, et al. Scaling up newborn care in Afghanistan: opportunities and challenges for the health sector. Health Policy Plan 2018;33:271-82.

4. Ministry of Public Health (MoPH). National reproductive, maternal, newborn, child, and adolescent health (RMNCAH) strategy, 2017-2021. Kabul, Afghanistan: Government of the Islamic Republic of Afghanistan.

5. Chou D, Daelmans B, Jolivet RR, et al. Ending preventable maternal and newborn mortality and stillbirths. BMJ 2015;351.

6. Dickson KE, Kinney MV, Moxon SG, et al. Scaling up quality care for mothers and newborns around the time of birth: an overview of methods and analyses of intervention-specific bottlenecks and solutions. BMC Pregnancy Childbirth 2015;15(Suppl 2):S1.

7. Kinney MV, Cocoman O, Dickson KE, et al. Implementation of the every newborn action plan: progress and lessons learned. Semin Perinatol 2015;39:326-37.

8. World Health Organization (WHO). Pregnancy, childbirth, postpartum and newborn care: a guide for essential practice, 2015.

9. Healthy Newborn Network. Available: https://www.healthynewbornne twork.org/issue/essential-newborn-care/ [Accessed 9 Mar 2018].

10. Vachon B, Désorcy B, Gaboury I, et al. Combining administrative data feedback, reflection and action planning to engage primary care professionals in quality improvement: qualitative assessment of short term program outcomes. BMC Health Serv Res 2015;15:391.

11. Taylor MJ, McNicholas C, Nicolay C, et al. Systematic review of the application of the plan-do-study-act method to improve quality in healthcare. BMJ Qual Saf 2014;23:290-8.

12. The World Bank. Progress in the Face of Insecurity: Improving Health Outcomes in Afghanistan. Washington DC: The World Bank, 2018.

13. Donabedian A. The quality of care. JAMA 1988;260:1743-8.

14. Campbell $\mathrm{H}$, Duke $\mathrm{T}$, Weber $\mathrm{M}$, et al. Global initiatives for improving hospital care for children: state of the art and future prospects. Pediatrics 2008;121:e984-92.

15. Kruk ME, Gage AD, Arsenault C, et al. High-quality health systems in the sustainable development goals era: time for a revolution. Lancet Glob Health 2018;6:e1196-252.

16. Kim Y-M, Zainullah P, Mungia J, et al. Availability and quality of emergency obstetric and neonatal care services in Afghanistan. Int J Gynaecol Obstet 2012;116:192-6.

17. Edward A, Kumar B, Kakar F, et al. Configuring balanced scorecards for measuring health system performance: evidence from 5 years evaluation in Afghanistan. PLoS Med 2011;8:e1001066.

18. Jhpiego. Afghanistan national maternal and newborn health quality of care assessment. Kabul, Afghanistan: Jhpiego, 2017.

19. de Graft-Johnson J, Vesel L, Rosen HE, et al. Cross-sectional observational assessment of quality of newborn care immediately after birth in health facilities across six sub-Saharan African countries. BMJ Open 2017;7:e014680.

20. ICF. The demographic health survey: service Provsion assessment (SPA), 2012.

21. Averting Maternal Death and Disability Program (AMDD). Needs assessment of emergency obstetric and newborn care (EmONC): facilitator's guide, 2010. 
22. Enweronu-Laryea C, Dickson KE, Moxon SG, et al. Basic newborn care and neonatal resuscitation: a multi-country analysis of health system bottlenecks and potential solutions. BMC Pregnancy Childbirth 2015;15(Suppl 2):S4.

23. Morgan MC, Dyer J, Abril A, et al. Barriers and facilitators to the provision of optimal obstetric and neonatal emergency care and to the implementation of simulation-enhanced mentorship in primary care facilities in Bihar, India: a qualitative study. BMC Pregnancy Childbirth 2018;18:420.

24. Mansoor GF, Chikvaidze P, Varkey S, et al. Quality of child healthcare at primary healthcare facilities: a national assessment of the integrated management of childhood illnesses in Afghanistan. Int $\mathrm{J}$ Qual Health Care 2017;29:55-62.

25. Tawfik Y, Rahimzai M, Ahmadzai M, et al. Integrating family planning into postpartum care through modern quality improvement: experience from Afghanistan. Glob Health Sci Pract 2014;2:226-33.

26. Lee ACC, Cousens S, Wall SN, et al. Neonatal resuscitation and immediate newborn assessment and stimulation for the prevention of neonatal deaths: a systematic review, meta-analysis and Delphi estimation of mortality effect. BMC Public Health 2011;11(Suppl 3):S12.

27. Hodgins S. Helping babies Breathe-Beyond training. Glob Health Sci Pract 2018;6:402-4. 